\title{
Escala de fontes de autoeficácia docente: Estudo exploratório com professores de Educação Física
}

\author{
Teacher self-efficacy source's scale: Exploratory study with physical Education Teachers
}

\author{
Roberto Tadeu laochite ${ }^{[a]}$, Roberta Gurgel Azzi[ ${ }^{[b]}$
}

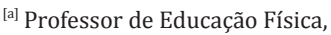
doutor em Educação Faculdade de Educação de Campinas (FE-Unicamp), professor do Departamento de Educação da Universidade Estadual Paulista (Unesp), Rio Claro, SP - Brasil, e-mail: iaochite@rc.unesp.br

[b] Psicóloga, doutora em Educação Faculdade de Educação de Campinas (FE-Unicamp), professora do Programa de Pós-Graduação em Educação da Universidade Estadual de Campinas (Unicamp), Campinas, SP - Brasil, e-mail: betazzi@uol.com.br
}

Recebido: 25/10/2010 Received: 10/25/2010

Aprovado: 29/03/2011 Approved: 03/29/2011

\section{Resumo}

Desde que Albert Bandura postulou a existência de quatro fontes de informação que influenciam a formação das crenças de autoeficácia, esforços têm sido empregados na tentativa de melhor compreender como avaliar e em que medida essas fontes podem contribuir para a constituição da crença de autoeficácia em contextos diversos. 0 presente estudo teve como objetivo explorar evidências de validade para o desenvolvimento de uma Escala de Fontes de Autoeficácia de Docentes (Efaed). Participaram 261 professores de escolas públicas e privadas da educação básica. Os sujeitos responderam a dois instrumentos, sendo um de caracterização e o outro a escala submetida para a avaliação. A escala foi composta por 16 itens divididos em quatro fatores, cada qual representando uma fonte de constituição da autoeficácia contextualizada para o ensino. Os dados foram submetidos à análise fatorial, de consistência interna e de correlação, utilizando-se, para isso, os recursos do software SPSS. Resultados confirmaram as postulações da teoria, porém os itens se posicionaram em fatores diferentes daqueles pensados nele. A consistência interna da escala total ( $\alpha$ de Cronbach) foi de 0,81 e as correlações entre os fatores foram baixas $(\mathrm{r}=0,118$ a 0,444$)$, porém positivas. Os resultados foram encorajadores para a continuidade das investigações com amostras maiores e com o apoio de outros instrumentos de investigação.

Palavras-chave: Autoeficácia. Ensino. Escala. 
was 0.81 and the correlations between factors were low ( $r=0,118$ to 0,444), although positive. The results were encouraging for the continuation of investigations with larger samples and with the support of other research tools.

Keywords: Self-efficacy. Teaching. Scale.

\section{Introdução}

Desde que Albert Bandura, em 1977, apresentou o construto da autoeficácia, inúmeros estudos em diferentes áreas do conhecimento têm constatado o poder preditivo e mediacional dessa crença, especialmente como um determinante crítico da motivação para o comportamento. Indivíduos que apresentam alta autoeficácia numa tarefa ou conjunto de subtarefas específicas, tendem a ser mais persistentes, motivados e com maiores probabilidades de sucesso. 0 inverso tem se mostrado verdadeiro nos estudos empíricos.

A literatura tem confirmado, ao longo desse tempo, a importância desse construto no que tange à dinâmica influência que exerce na direção das ações do professor e das decorrências dessas no processo ensino-aprendizagem em diferentes áreas como o ensino de Matemática, de Ciências, do uso de tecnologias, bem como em contextos educacionais diversos.

Bandura (1997) afirma que a tarefa de criar ambientes de aprendizagem, isto é, estruturar atividades acadêmicas que conduzam ao desenvolvimento de competências apresenta forte relação com a autoeficácia dos professores e isso afeta a orientação dos professores em relação ao processo educacional. Segundo ele, professores com forte senso de autoeficácia instrucional acreditam que, por meio de esforços extras, são capazes de ensinar os alunos, inclusive aqueles que apresentam mais dificuldades. Ao contrário, professores com fraco senso de autoeficácia instrucional acreditam que pouco podem fazer quando há desmotivação dos alunos.

Os estudos sobre as crenças de autoeficácia no domínio do ensino têm investigado diferentes níveis de ensino e contextos que vão desde a educação básica até o ensino superior, de escolas urbanas às rurais etc. $\mathrm{O}$ interesse nesses estudos ocorre na medida em que a autoeficácia exerce um papel preditivo e mediacional na prática docente, na motivação, persistência e autorregulação dos alunos, nas tomadas de decisão da equipe administrativa da escola (Bandura, 1997; Tschannen-Moran \& Gareis, 2004; Tschannen-Moran \& Woolfolk Hoy, 2000; Woolfolk Hoy \& Burke Spero, 2005; Zimmerman, 1995; Zimmerman \& Cleary, 2006).

Autoeficácia docente é, segundo Woolfolk Hoy e Burke Spero (2005), um julgamento orientado para o futuro que tem a ver mais com a percepção de capacidade do que com o grau atual de competência. As autoras apontam que essa é uma distinção importante, pois de maneira geral, as pessoas superestimam ou subestimam o grau atual de suas capacidades e isso pode trazer consequências para as ações que desejam realizar. É importante destacar que o construto da autoeficácia docente é multifatorial e está relacionado com os requisitos da tarefa de ensinar num contexto e matéria específicos (Tschannen-Moran, Woolfolk Hoy \& Hoy, 1998).

Bandura (1997) ressalta que o valor do autodiagnóstico para julgar a autoeficácia dependerá da dificuldade da ação a ser feita, das diversas habilidades e sub-habilidades exigidas, da relação de similaridade entre o que a ação exige com o que outras ações já conhecidas requerem e dos fatores contextuais que podem incluir impedimentos, suporte externo, adequação de recursos e circunstâncias em que a ação ocorre.

Pautados nos pressupostos da teoria social cognitiva, Tschannen-Moran, Woolfolk Hoy e Hoy (1998) afirmam que, ao fazer um julgamento da própria eficácia, o professor leva em consideração o que é exigido dele na situação de ensino em conjunto com as demandas do contexto (ambiente) no qual exerce a prática pedagógica. Essa avaliação produz inferências sobre a relação dificuldade versus habilidades e capacidades necessárias que precisa ter para obter sucesso na realização da tarefa de ensinar.

No âmbito da docência, alguns desses fatores necessários são os graus de capacidade e de motivação dos alunos para aprender, as estratégias que o professor pode utilizar para ensinar, os materiais e o espaço disponíveis, a liderança do diretor, o clima 
motivacional da escola, o suporte recebido de outros professores etc. Em outras palavras e, na perspectiva da docência, a autoeficácia contribui para a determinação de como os professores se sentem, pensam, se automotivam e se comportam em relação aos seus pensamentos, ao contexto que vivenciam e às ações que realizam no cotidiano da prática docente ao desempenharem as tarefas ligadas ao processo ensino-aprendizagem no âmbito escolar e, em muitos casos, extraescolar.

Bandura (1997) postulou a existência de quatro fontes de informação que influenciam a formação das crenças de autoeficácia. Esforços têm sido empregados na tentativa de melhor compreender em que medida e como essas fontes contribuem para a constituição dessas crenças. Uma vez que a constituição da autoeficácia é foco no presente estudo torna-se necessário compreender esse processo tendo como guia as orientações apresentadas pelo próprio Bandura. Ele aponta que essa compreensão pode se dar pelo processamento de informação, advinda de uma ou de várias fontes e que, nesse processo, a informação é avaliada cognitivamente pela autorreflexão que o indivíduo realiza e tão importante quanto identificar a origem da informação, isto é, a fonte, é compreender como os indivíduos avaliam e integram essa informação que contribuirá para o estabelecimento das crenças de autoeficácia para uma dada atividade.

No contexto da docência, as fontes de informação da autoeficácia docente se manifestam dentro dessas quatro possibilidades e estão relacionadas com as situações vivenciadas no transcorrer das mais diversas situações ligadas à prática pedagógica, como, por exemplo, no manejo da sala, na proposição de tarefas adequadas ao nível dos alunos e na respectiva mediação quando na realização das tarefas solicitadas, na mobilização dos alunos para aprenderem, nos encontros pedagógicos com a direção, supervisão e demais colegas da escola, em situações de reuniões com pais etc.

As experiências de ensino vividas diretamente (experiências diretas de domínio) pelo professor no cotidiano da prática pedagógica se constituem na forma mais efetiva de se criar um forte senso de eficácia. Um dos aspectos importantes desse tipo de fonte, e que vai além dos resultados obtidos na realização da tarefa, é o fornecimento de informação acerca da capacidade e não apenas o desempenho obtido pelo professor. Segundo Bandura (1997), o desempenho por si só não fornece informação suficiente para julgar o nível de capacidade de alguém. Quando as pessoas experimentam o sucesso obtido de forma fácil, têm poucas chances de persistir quando o fracasso acontece. Por outro lado, quando alguém obtém êxito na atividade e esse resultado é avaliado como positivo e derivado do próprio esforço na superação de obstáculos presentes na atividade e/ ou no ambiente, isso geralmente aumenta a crença na própria capacidade para executar esta atividade ou atividades similares (Bandura, 1997).

Um segundo caminho de construção das crenças de autoeficácia é por meio das experiências aprendidas via observação de modelos sociais. Isto é, à medida em que se observa direta ou indiretamente o esforço e a persistência de pessoas na realização de um dado comportamento, cujas características sejam similares (ainda que isso não seja o fator principal, mas pode potencializar a informação) às do observador, isso pode gerar a percepção de que também se pode ser capaz de se comportar da mesma forma. A respeito do potencial dessas experiências na constituição e aumento da crença de autoeficácia Bandura (1997, p. 88) destaca que “[...] modelos competentes transmitem conhecimento e ensinam aos observadores habilidades efetivas e estratégias para gerenciar as demandas do ambiente".

No que se referem às experiências vicárias no campo da docência, observar outros professores ministrando aulas, assistir a filmes e vídeos relacionados à docência são alguns dos exemplos de como esse tipo de fonte pode contribuir para formação da autoeficácia docente. Para Tschannen-Moran, Woolfolk Hoy e Hoy (1998), professores considerados como modelos de sucesso são bases para mostrar que ensinar pode ser uma tarefa possível de ser manejada e que os recursos pessoais e do contexto podem ser adequados.

A persuasão social pode ser entendida como outra fonte de informação que influencia no julgamento sobre as crenças de capacidade. A persuasão social funciona na medida em que se busca persuadir o outro, em geral, verbalmente, para que haja um aumento do esforço e de forma contínua, principalmente quando há a necessidade de superação dos desafios presentes na atividade e no contexto em que essa é desenvolvida. Além dessa função, a persuasão pode favorecer as crenças de autoafirmação de maneira que essas criam autoincentivos para o desenvolvimento do nível de habilidade, de crenças 
de autoeficácia e podem fornecer informação de desempenho por meio de feedback (Bandura, 1997).

Bandura $(1986,1997)$ afirma que o impacto que a persuasão pode causar na constituição da crença depende da credibilidade, do conhecimento e da experiência da fonte persuasiva na atividade em questão. Afirma, ainda, que apenas dizer às pessoas o quanto são capazes, pouco contribui para o fortalecimento das crenças de autoeficácia, uma vez que melhor seria se essas pessoas aumentassem o grau de habilidade pessoal na atividade, já que a persuasão social serve como parte de um conjunto de procedimentos para o ganho de habilidade e de confiança na atividade, para a diminuição da incerteza de que se pode ser capaz de realizar, aspectos esses que poderão interferir na constituição da autoeficácia.

A quarta fonte de informação da crença de autoeficácia é denominada de estados fisiológicos e afetivos. Nível de ativação (arousal), fadiga, estresse, ansiedade, tensão, dor, estados de humor são manifestações que podem alterar a percepção de autoeficácia, pois afetam diretamente o julgamento que as pessoas fazem sobre a própria capacidade para realizar determinada tarefa. 0 desencadeamento de diferentes reações psicofisiológicas - sudorese excessiva, queda de pressão arterial, alteração da frequência cardíaca, dor, fadiga, ansiedade, medo, confiança excessiva podem alterar a crença de quão competente alguém pode se avaliar e assim diminuir (ou não) a mobilização de esforços para a realização de uma dada tarefa (Bandura, 1986, 1997; Mulholland \& Wallace, 2001; Tscahnnen-Moran, Woolfolk Hoy \& Hoy, 1998).

Quanto aos estados afetivos Bandura (1997) encontrou relações entre as crenças de autoeficácia e os estados de humor. Afirma que os resultados de estudos que investigaram essas relações apoiam a afirmativa de que o impacto do humor sobre as crenças de autoeficácia é parcialmente mediado pela lembrança seletiva das experiências passadas de sucesso e fracasso que um indivíduo armazena na memória.

Estudos anteriores investigaram as fontes de autoeficácia em diferentes situações. Resultados dessas investigações revelam que experiências diretas de domínio, vicárias, persuasão social e estados fisiológicos foram fontes preditivas, em diferentes combinações, da autoeficácia para aprender Matemática (Lopez \& Lent, 1992; Luzzo et al., 1999; Matsui et al., 1990; Stevens et al., 2006; Usher \& Pajares, 2006).
Já os estudos de Pajares (1994) e Pajares, Johnson e Usher (2007) buscaram avaliar as fontes de autoeficácia na atividade de escrita. Numa ampla revisão de literatura sobre as fontes de autoeficácia na escola, Usher e Pajares (2008) apresentam além dos estudos já realizados, sobretudo no contexto da Matemática, um conjunto de sugestões que podem contribuir para novas investigações nesse campo da formação das crenças de autoeficácia no contexto acadêmico.

Os resultados dos estudos aqui citados se afinam com as postulações de Bandura (1997) sobre a constituição das fontes de autoeficácia, quando o autor afirma que isso pode se dar pelo processamento de informação, advinda de uma ou de várias fontes e que, nesse processo, a informação é avaliada cognitivamente pela autorreflexão e pelo valor que o indivíduo atribui a cada uma dessas fontes.

No que diz respeito à construção de instrumentos para avaliar fontes de autoeficácia, Kieffer e Henson (2000) propuseram um inventário de tais fontes (Sources of Self-Efficacy Inventory) cujo desenvolvimento pautou-se no modelo de autoeficácia docente proposto por Tschannen-Moran, Woolfolk Hoy e Hoy (1998) e se constituiu por quatro fatores representando as fontes de constituição da autoeficácia sendo: experiências diretas de domínio (9 itens), experiência vicária (9 itens), persuasão social (10 itens) e estados fisiológicos e emocionais (7 itens). Resultados da análise fatorial confirmatória, segundo os autores, não confirmaram a distribuição dos itens em suas respectivas fontes, fato que indicou a necessidade de outras análises após a revisão do instrumento.

Polou (2007) explorou alguns fatores que precedem a constituição da autoeficácia para ensinar de estudantes gregos em formação para a docência. Para tanto, construiu um instrumento denominado de "Inventário de fontes de eficácia do professor" (Teacher Efficacy Sources Inventory). A escala é constituída por 30 itens compreendendo as fontes de eficácia para ensinar, os quais se dividiram em sete dimensões com alfa de Cronbach variando entre 0,72 e 0,79. As dimensões são: características pessoais (6 itens), capacidades/habilidades (4itens), motivação (4itens), experiência direta com persuasão social/social (6 itens), experiências vicárias (4 itens), estados fisiológicos/afetivos (3 itens), treinamento na universidade ( 3 itens). As três primeiras dimensões foram as mais pontuadas pelos participantes, enquanto que "experiências vicárias" e "estados fisiológicos e afetivos" receberam as menores pontuações. 
A autora reconheceu como limitação do instrumento os baixos índices de confiabilidade dos itens da escala.

Considerando que não há instrumentos dessa natureza e com essa finalidade no cenário nacional, a estrutura da escala foi construída sob os pressupostos da teoria da autoeficácia proposta por Bandura (1997), sobretudo nos apontamentos sobre a natureza da constituição das crenças de autoeficácia, considerando as quatro fontes de informação da autoeficácia. Além disso, a construção do instrumento procurou contemplar as diretrizes indicadas pelo mesmo autor em estudos posteriores (Bandura, 2006) e nas proposições de Kieffer e Henson (2000), Prieto (2005), Tschannen-Moran, Woolfolk Hoy e Hoy (1998) e Tschannen-Moran e Woolfolk Hoy (2001).

Assim, o presente estudo, de natureza exploratória, objetivou buscar evidências de validade para o desenvolvimento de uma Escala de Fontes de Autoeficácia de Docentes (EFAED).

\section{Método}

Sujeitos

Participaram do estudo 261 sujeitos, sendo $44,5 \%$ do gênero masculino e $55,5 \%$ do gênero feminino, com faixa etária entre 21 e 60 anos, média de 35,5 anos e desvio padrão de 8,66 anos. Todos os participantes têm a licenciatura como formação inicial, os quais a concluíram entre 1973 e 2005, sendo que 5,4\% antes de 1980, 30,1\% entre 1991 e $1990,33,8 \%$ entre 1991 e 2000 e $30,7 \%$ entre 2001 e 2005 . 0 tempo médio de atuação dos professores foi de 10,6 anos e desvio padrão de 7,9 anos. A grande maioria, isto é, $84 \%$ trabalha em escolas públicas, 6,9\% em escolas privadas e 9,1\% atuam em ambos os tipos de escola, de maneira que $80,6 \%$ dos professores lecionavam para o ensino fundamental e 19,3\% para o ensino médio.

Instrumentos

Foram utilizados dois instrumentos para a coleta dos dados: 1) Questionário de caracterização do participante e de sua atividade docente elaborado para a finalidade do estudo e tendo como objetivo identificar as características do participante - idade, gênero, ano de conclusão da graduação, tempo de formação e de sua atividade docente em relação ao nível de atuação, tipo de escola, infraestrutura, número de alunos, apoio recebido de colegas e corpo administrativo entre outros; 2) Escala de Fontes de Autoeficácia de Docentes (EFAED) elaborada pelos autores do estudo em questão. A escala é do tipo Likert de 6 pontos com 16 itens igualmente distribuídos em quatro dimensões a saber:

a) experiência direta;

b) experiência vicária;

c) persuasão social;

d) estados fisiológicos e emocionais.

Os procedimentos utilizados para a construção do instrumento foram:

a) estudo teórico do construto, especificamente sobre a constituição das crenças de autoeficácia;

b) criação de seis itens para cada dimensão considerando os apontamentos teóricos (Bandura, 1997, 2006);

c) descrição dos itens em afirmativas representando, de maneira geral, o contexto do ensino para avaliação segundo uma escala Likert de 1 (totalmente falso) a 6 (totalmente verdadeiro), com vistas à concordância;

d) formatação dos itens de maneira aleatória, escritos na primeira pessoa do singular e submetidos para a avaliação.

A escala EFAED foi submetida à análise de dois juízes especialistas no referencial teórico utilizado e na construção de instrumentos de avaliação. Os juízes tiveram como objetivos avaliar a pertinência dos itens quanto à clareza, precisão teórica, linguagem, simplicidade e adequabilidade conforme procedimentos metodológicos realizados por Polydoro, Winterstein, Azzi, Carmo, Venditti Jr. (2004). A configuração final do instrumento se deu após a convergência dos pareceres e aceite final de ambos os juízes da versão apresentada.

\section{Procedimentos}

Após a explicação sobre o preenchimento dos instrumentos e o consentimento dos participantes, os instrumentos foram preenchidos em dois contextos diferentes: a) em cursos de pós-graduação, 
b) em cursos de capacitação profissional. 0 preenchimento ocorreu de forma coletiva, numa única sessão e contou com os seguintes procedimentos: a explicação dos objetivos do estudo, orientações sobre como preencher os instrumentos, da possibilidade de desistência em qualquer momento, preenchimento pelos participantes e devolução dos instrumentos preenchidos. O tempo de aplicação dos instrumentos foi de 15 a 25 minutos incluindo todos os procedimentos. Para a análise dos dados utilizou-se o programa estatístico Social Statistical Package for the Social Sciences (SPSS), v. 13.0. Testou-se a confiabilidade da digitação dos dados por meio dos procedimentos de inspeção visual da planilha e escolha aleatória de $20 \%$ dos casos para conferência.

\section{Resultados}

\section{Adequação da amostra}

A amostra foi adequada para medir as fontes de autoeficácia docente, conferindo validade aos resultados encontrados. 0 valor encontrado para a medida de adequação da amostra de Kaiser-MeyerOlkin foi igual a 0,826 , indicando um resultado altamente satisfatório.

Foi utilizado o teste de esfericidade de Bartlett que permitiu avaliar a hipótese de que houve igualdade de variância-covariância nos grupos estudados, isto é, que a matriz de correlação é uma matriz identidade $\left.\chi_{\text {aproximado }}^{2}(120)=1150,065 ; p<0,001\right)$. A análise da matriz de correlação entre os itens da escala revelou que a grande maioria das correlações é superior a $0,30(90,8 \%)$ e todas altamente significativas ( $p<0,001)$, satisfazendo um dos pressupostos para que a amostra seja apropriada para a análise fatorial (Hair Jr., Anderson, Tatham, Black, 2005).

\section{Análise fatorial}

A análise fatorial de componentes principais com rotação varimax mostrou que apenas quatro fatores tiveram autovalores maiores ou iguais a 1,0 e responderam a 57,37\% da variância total, conforme dados apresentados na Tabela 1 .

Tabela 1 - Distribuição dos autovalores e variação explicada por fator

\begin{tabular}{cccc}
\hline \multirow{2}{*}{ Fator } & Autovalor & \multicolumn{2}{c}{ Variância (\%) } \\
\cline { 3 - 4 } & & Simples & Acumulada \\
\hline 1 & 4,361 & 27,254 & 27,254 \\
2 & 2,394 & 14,962 & 42,216 \\
\hline 3 & 1,370 & 8,565 & 50,782 \\
\hline 4 & 1,054 & 6,588 & 57,369 \\
\hline 5 & 0,821 & 5,133 & 62,502 \\
\hline 6 & 0,802 & 5,014 & 67,516 \\
\hline 7 & 0,692 & 4,328 & 71,844 \\
\hline 8 & 0,652 & 4,075 & 75,919 \\
\hline 9 & 0,619 & 3,871 & 79,790 \\
\hline 10 & 0,585 & 3,656 & 83,445 \\
\hline
\end{tabular}

Fonte: Dados da pesquisa.

As comunalidades se referem à porcentagem de variância explicada de cada item em relação à escala como um todo e são aceitos os itens com valores acima de 0,30 . Na Tabela 2 foi apresentada a matriz rotacionada dos componentes principais de forma que todos os itens apresentaram comunalidades acima de 0,30 e compuseram a distribuição nos fatores.

Tabela 2 - Matriz rotacionada de componentes principais da Escala EFAED

(Continua)

\begin{tabular}{|c|c|c|c|c|c|}
\hline Item & Fator 1 & Fator 2 & Fator 3 & Fator 4 & Comunalidade \\
\hline $\begin{array}{l}5 \text { - As experiências diretas de domínio da minha prática docen- } \\
\text { te afetam o que penso sobre minha capacidade para ensinar. }\end{array}$ & & & & 0,688 & 0,592 \\
\hline $\begin{array}{l}13 \text { - Enfrentar situações desafiadoras e que despendem mais } \\
\text { esforço como professor (a), contribui para o que penso sobre } \\
\text { minha capacidade para ensinar. }\end{array}$ & & & & 0,670 & 0,673 \\
\hline $\begin{array}{l}12 \text { - A percepção de sentimentos positivos durante minha prá- } \\
\text { tica docente contribui quando penso sobre minha capacidade } \\
\text { para ensinar. }\end{array}$ & & & & 0,624 & 0,705 \\
\hline
\end{tabular}


Tabela 2 - Matriz rotacionada de componentes principais da Escala EFAED

(Conclusão)

\begin{tabular}{|c|c|c|c|c|c|}
\hline Item & Fator 1 & Fator 2 & Fator 3 & Fator 4 & Comunalidade \\
\hline $\begin{array}{l}2 \text { - Observar professores habilidosos dando aulas contribui para } \\
\text { o que penso sobre minha capacidade para ensinar. }\end{array}$ & & & 0,756 & & 0,612 \\
\hline $\begin{array}{l}6 \text { - Assistir a filmes e/ou a vídeos de professores competen- } \\
\text { tes contribui para o que penso sobre minha capacidade para } \\
\text { ensinar. }\end{array}$ & & & 0,720 & & 0,597 \\
\hline $\begin{array}{l}1 \text { - } 0 \text { que penso sobre minha capacidade para ensinar diz res- } \\
\text { peito às experiências vividas e que foram importantes para mim. }\end{array}$ & & & 0,616 & & 0,465 \\
\hline $\begin{array}{l}10 \text { - Quando visualizo mentalmente experiências de sucesso em } \\
\text { minha prática docente, isso contribui para o que penso sobre } \\
\text { minha capacidade para ensinar. }\end{array}$ & & 0,737 & & & 0,559 \\
\hline $\begin{array}{l}11 \text { - Receber comentários dos meus alunos avaliando minha } \\
\text { prática docente influencia o que penso sobre minha capacidade } \\
\text { para ensinar. }\end{array}$ & & 0,724 & & & 0,557 \\
\hline $\begin{array}{l}15 \text { - Ouvir comentários de pessoas que admiro reconhecendo } \\
\text { o meu progresso como professor (a) afeta o que penso sobre } \\
\text { minha capacidade para ensinar. }\end{array}$ & & 0,644 & & & 0,499 \\
\hline $\begin{array}{l}3 \text { - Ouvir comentários sobre meu trabalho como professor (a), } \\
\text { feitos por professores que admiro, influencia o que penso sobre } \\
\text { minha capacidade para ensinar. }\end{array}$ & & 0,600 & & & 0,599 \\
\hline $\begin{array}{l}14 \text { - Observar professores competentes explicando sobre a prá- } \\
\text { tica docente - o que fazem, como fazem etc, - influencia o que } \\
\text { penso sobre minha capacidade para ensinar. }\end{array}$ & & 0,560 & & & 0,543 \\
\hline $\begin{array}{l}9 \text { - Quando cometo erros, isso afeta o que penso sobre minha } \\
\text { capacidade para ensinar. }\end{array}$ & 0,761 & & & & 0,621 \\
\hline $\begin{array}{l}8 \text { - Sintomas como o cansaço, dores, irritação são indicativos } \\
\text { que afetam o que penso sobre minha capacidade para ensinar. }\end{array}$ & 0,753 & & & & 0,580 \\
\hline $\begin{array}{l}7 \text { - Comentários que desvalorizam minha prática docente afetam } \\
\text { o que penso sobre minha capacidade para ensinar. }\end{array}$ & 0,734 & & & & 0,572 \\
\hline $\begin{array}{l}16 \text { - Mudanças no meu humor durante minha prática como pro- } \\
\text { fessor afetam o que penso sobre minha capacidade para ensinar. }\end{array}$ & 0,703 & & & & 0,556 \\
\hline $\begin{array}{l}4 \text { - Quando percebo que estou ansioso (a), isso afeta o que penso } \\
\text { sobre minha capacidade para ensinar. }\end{array}$ & 0,584 & & & & 0,450 \\
\hline
\end{tabular}

Fonte: Dados da pesquisa.

Neste trabalho, foi assumida a configuração de acordo com a Análise Fatorial Exploratória, a saber: o fator 1 corresponde aos estados fisiológicos e emocionais e é composto dos itens $4,7,8,9$ e 16.0 fator 2 se refere à persuasão social e é composto dos itens $3,10,11,14$ e 15. 0 fator 3 se refere às experiências vicárias e é composto dos itens 1,2 e 6. Por fim, o fator 4 trata das experiências diretas de domínio com os itens 5, 12 e 13. Como é possível observar na Tabela 2, os itens não se agruparam conforme suas respectivas dimensões de origem, isto é, pelo referencial da teoria seria esperado que o agrupamento dos itens ocorresse segundo as fontes de constituição da autoeficácia. Nesse caso, os itens 1, 5, 9 e 11 pertenceriam à fonte "experiências diretas de domínio", os itens 2, 6, 10 e 14 à "experiências vicárias", os itens 3, 7, 11 e 15 à "persuasão social" e os itens 4, 8, 12 e 16 à "estados fisiológicos e emocionais".

\section{Análise da consistência interna e correlação}

A análise da consistência interna dos 16 itens da escala resultou com 261 casos válidos, resultou em 
uma média de 67,85 pontos e desvio padrão de 11 , 26. Os resultados indicaram que a Escala de Fontes de Autoeficácia Docente apresentou uma consistência alfa de Cronbach geral de 0,81, o que sugere uma alta consistência interna da escala e demonstra que os itens intercalados ao longo da escala medem o mesmo construto ou construtos bastante semelhantes. Portanto também foi feita a análise da consistência interna para cada um dos quatro fatores que passaram a compor a Escala de Fontes de Autoeficácia Docente, como mostrado na Tabela 3.

Tabela 3 - Estatísticas descritivas e confiabilidade da EFAED de acordo com os grupos de variáveis

\begin{tabular}{|c|c|c|c|c|}
\hline Variáveis & $\begin{array}{l}\text { Casos } \\
\text { válidos }\end{array}$ & Média & $\begin{array}{l}\text { Desvio } \\
\text { Padrão }\end{array}$ & $\begin{array}{l}\text { Alfa de } \\
\text { Cronbach }\end{array}$ \\
\hline $\begin{array}{l}\text { Fator } 1 \text { - Esta- } \\
\text { dos fisiológicos } \\
\text { e emocionais }\end{array}$ & 261 & 15,69 & 5,92 & 0,7800 \\
\hline $\begin{array}{l}\text { Fator } 2 \text { - Per- } \\
\text { suasão social }\end{array}$ & 261 & 23,54 & 4,57 & 0,7595 \\
\hline $\begin{array}{l}\text { Fator } 3 \text { - } \\
\text { Experiências } \\
\text { Vicárias }\end{array}$ & 261 & 14,07 & 2,84 & 0,5896 \\
\hline $\begin{array}{l}\text { Fator } 4 \text { - } \\
\text { Experiências } \\
\text { diretas de } \\
\text { domínio }\end{array}$ & 261 & 14,55 & 2,61 & 0,5863 \\
\hline $\begin{array}{l}\text { Escala de } \\
\text { Fontes de } \\
\text { Autoeficácia } \\
\text { Docente }\end{array}$ & 261 & - & - & 0,8109 \\
\hline
\end{tabular}

Fonte: Dados da pesquisa.

Os resultados da consistência interna entre os fatores mostram que os fatores 1 e 2 apresentaram coeficientes (alfa de Cronbach) satisfatórios, sendo 0,78 e 0,75 respectivamente. Já os fatores 3 e 4 apresentaram coeficientes medianamente satisfatórios 0,58 para ambos.

Os resultados da correlação entre os fatores, a partir da identificação do coeficiente de correlação $r$ de Pearson da escala revelam que, embora os valores das correlações alternem entre baixos e moderados $(r=0,118$ e 0,444$)$, todas as correlações foram positivas e significativas entre as fontes (Tabela 4).
Tabela 4 - Matriz de Correlação entre os fatores da EFAED

\begin{tabular}{lcccc}
\hline & F1 & F2 & F3 & F4 \\
\hline F1 & 1 &, $253^{* *}$ &, $118^{*}$ &, $252^{* *}$ \\
F2 & & 1 &, $409^{* *}$ &, $444^{* *}$ \\
F3 & & & 1 &, $283^{* *}$ \\
F4 & & & & 1 \\
\hline
\end{tabular}

** Correlação é significativa ao nível de 0.01 .

* Correlação é significativa ao nível de 0.05 .

F1 = Estados afetivos e fisiológicos $\quad$ F2 = Persuasão social F3 = Experiências vicárias F4 = Experiências diretas de domínio

Fonte: Dados da pesquisa.

\section{Discussão}

A distribuição dos itens nos fatores se deu de forma um pouco diferenciada do que foi pensado teoricamente. A construção da escala pautou-se nos apontamentos feitos por Bandura (1997, 2006) acerca da constituição das fontes de informação da autoeficácia e da construção de escalas para mensurar o construto e em parte da literatura disponível sobre fontes de autoeficácia, sobretudo em estudos cujo instrumento de medida procurava medir a autoeficácia docente (Kieffer \& Henson, 2000; Palmer, 2006; Prieto, 2005). Foi estabelecida, a priori, uma escala com quatro fatores, de maneira que cada fator representava uma fonte de informação da autoeficácia. Para cada fator, foram propostos quatro itens elaborados a partir da literatura disponível sobre o objeto de avaliação.

$\mathrm{Na}$ análise, os itens relacionados ao fator 1 estados fisiológicos e emocionais - expressam, geralmente, uma relação com reações psicofisiológicas desencadeadas quando o julgamento de eficácia do indivíduo está em desacordo com a exigência da tarefa e das condições em que essa ocorre. A entrada dos itens 7 e 9, ligados à persuasão e experiências diretas de domínio respectivamente, pode ter se dado em função da interpretação do conteúdo desses itens pelos participantes. É possível que os participantes tenham relacionado a ideia de receber comentários negativos e de cometer erros como algo negativo e gerador de estados emocionais desagradáveis. 
Quanto ao fator 2 - persuasão social - os itens 3, 11 e 15 representam os itens diretamente ligados a essa fonte, porém houve a migração dos itens 10 e 14, originalmente ligados às experiências vicárias. Bandura (1997) explica que a persuasão social pode se dar por meio de feedbacks informando e atribuindo um valor ao desempenho obtido. Fatores como a credibilidade da fonte persuasiva, a forma e o contexto em que ocorre a persuasão, além do grau de disparidade entre o julgamento que as pessoas fazem das próprias capacidades com a informação (feedback) que está sendo oferecido em determinado momento interferem no resultado dessa fonte de constituição. A entrada de itens relativos à fonte de experiências vicárias pode estar ligada à redação desses itens cujos termos "visualizo mentalmente" e "professores competentes explicando..." podem ter sido interpretados como uma forma de autopersuasão e persuasão social, respectivamente.

Para o fator 3 - experiências vicárias - três dos itens estão em consonância com as características apontadas pela literatura quanto a essa fonte de autoeficácia, uma vez que procuram representar as condições de aprendizagem por observação, foco principal dessa fonte. Para Bandura (1997), a modelação funciona como uma ferramenta efetiva para promover a percepção de autoeficácia. Assim, segundo ele, a possibilidade de observar pessoas com condições similares às do observador, além das inúmeras possibilidades causadas pela observação de modelos simbólicos presentes nas mais diversas fontes midiáticas e mesmo a possibilidade de se automodelar a partir da observação, por meio de videofilmagens das próprias ações.

Finalmente, quanto ao fator 4 - experiências diretas de domínio - apenas o item 12 não se enquadra na explicação teórica para o fator em questão, uma vez que o conteúdo do item está mais relacionado com os estados fisiológicos e emocionais. Novamente, o conteúdo do item pode ter levado o professor a focalizar sua resposta no aspecto de pensar na própria prática "...durante minha prática docente..." ao invés de pensar nos sentimentos positivos, o que caracterizaria os estados emocionais. Bandura (1997) declara que as experiências diretas de domínio são a maior fonte de informação na constituição da crença de autoeficácia, pois essas evidenciam a percepção de competência na realização de uma tarefa ou comportamento. Outra característica dessa fonte está relacionada com a capacidade do indivíduo para o enfrentamento de desafios e de despender esforço extra para superá-los.
Com relação à consistência interna total da escala, embora o valor tenha sido satisfatório, alguns fatores apresentaram valores considerados medianamente satisfatórios, resultado que pode ser graças à pequena quantidade de itens que, juntos, não sejam uma combinação suficiente para compor esses fatores, ou, conforme nos orienta Cortina (1993), afirmando que o alfa de Cronbach pode modificar o seu resultado em função do número de itens, da intercorrelação entre os itens e da dimensionalidade. Os valores do presente estudo estão próximos dos valores encontrados por Polou (2007).

Quanto à correlação entre os fatores da escala, embora os valores das correlações alternem entre baixos e moderados ( $\mathrm{r}=0,118$ e 0,444$)$, todas as correlações foram positivas e significativas entre as fontes, conforme mostrados na Tabela 4. Resultados semelhantes foram encontrados nos estudos de Hampton e Mason (2003) e Stevens et al. (2006).

As correlações mais fortes e significativas ocorreram entre as fontes de persuasão social, experiências vicárias e experiências diretas de domínio. Isso requer certa atenção, pois indica que os fatores podem não estar se diferenciando suficientemente uns dos outros, o que sugere uma revisão na composição dos itens. Embora algumas dessas correlações tenham sido apenas moderadas, há que se refletir sobre a indicação de Usher e Pajares (2008, p. 781) no sentido de que "altas correlações entre as fontes indicam a necessidade de discriminação entre os itens usados para medi-las".

Por outro lado, esses valores reafirmam o que já foi exposto anteriormente sobre o não agrupamento dos itens conforme esperado segundo a composição inicial da escala realizada sob os pressupostos teóricos do referencial da autoeficácia.

Na literatura, essas relações também apareceram nos estudos de Hampton e Mason (2003) e de Pajares et al. (2007). A explicação para essas correlações significativas entre as fontes vem de Bandura (1997) quando o autor, como já mencionado anteriormente, afirma sobre a necessidade de se compreender que a informação vinda de uma ou mais fontes é avaliada cognitivamente pelo indivíduo e, portanto, dependente do peso (valor) que esse atribuirá a cada uma delas por meio de processos autorreflexivos.

\section{Considerações finais}

A investigação sobre as fontes de constituição da crença de autoeficácia de professores é recente, e a 
escassez da produção se constitui em motivação para a realização de novos estudos. Tendo como objetivo principal buscar evidências psicométricas que, nesse primeiro estudo exploratório, possibilitem a utilização do instrumento EFAED em situações cujo domínio seja a docência, tal esforço apresenta resultados encorajadores no tocante à continuidade de novas investigações nessa direção. É necessário salientar que outras aplicações do instrumento com professores de disciplinas diferentes e em contextos diversos poderão contribuir tanto para o refinamento como para a amplitude da aplicação do instrumento aqui proposto. Ressalta-se, ainda, que os valores encontrados nessa investigação sugerem tal iniciativa, principalmente com vistas à confirmação da validade do construto para o contexto do ensino no cenário brasileiro.

A investigação das fontes de constituição da autoeficácia de professores parece ser de grande importância para os estudos sobre o construto em questão, sobretudo para a formação de professores no que diz respeito à reorganização de práticas pedagógicas que possam favorecer a promoção e ao fortalecimento da crença de autoeficácia dos professores, bem como no sentido de compreender a gênese dessa crença. Nesse sentido, identificar e compreender quais são as fontes de constituição mais proeminentes podem facilitar esse processo. Ainda nessa direção de buscar possibilidades, é importante destacar que a utilização da escala acompanhada de outros instrumentos pode ser um caminho bastante promissor na aquisição de dados que permitam uma compreensão mais ampla acerca da Autoeficácia Docente e de suas fontes de constituição.

\section{Agradecimentos}

Os autores agradecem imensamente à Marilda Aparecida Dantas e à Cacilda E.A. Alvarenga pela leitura e sugestões dadas ao trabalho.

\section{Referências}

Bandura, A. (1986). Social foundations of thought and action: A social cognitive theory. New Jersey: Prentice-Hall Inc.; Englewood Cliffs.

Bandura, A. (1997). Self-efficacy: The exercise of control. New York: Freeman.
Bandura, A. (2006). Guide for creating self-efficacy scales. In F. Pajares \& T. Urdan (Ed.). Self-efficacy beliefs of adolescents (pp. 307-338). Greenwich: Information Age Publishing.

Cortina, J. M. (1993). What is coefficient alpha? An examination of theory and applications. Journal of Applied Psychology, 78(1), 98-104.

Hair Jr., J. F., Anderson, R. E., Tatham, R. L., \& Black, W. C. (2005). Análise multivariada de dados. Porto Alegre: Bookman.

Hampton, N. Z., \& Mason, E. (2003). Learning disabilities, gender, sources of self-efficacy, self-efficacy beliefs, and academic achievement in high school students. Journal of School Psychology, 1(2), 101-112.

Kieffer, K. M., \& Henson, R. K. (2000). Development and validation of the Sources of Self-Efficacy Inventory (SOSI): Exploring a new measure of teacher efficacy. Paper presented at the Annual Meeting of the National Council on Measurement in Education, New Orleans.

Lopez, F. G., \& Lent, R. W. (1992). Sources of mathematics self-efficacy in high school students. Career Development Quarterly, 41(1), 3-12.

Luzzo, D. A., Hasper, P., Albert, K. A., Bibby, M. A., \& Martinelli, E. A. (1999). Effects of self-efficacy-enhancing interventions on the math/science career interests, goals, and actions of career undecided college students. Journal of Counseling Psychology, 46(2), 233-243.

Matsui, T., Matsui, K., \& Ohnishi, R. (1990). Mechanisms underlying math self-efficacy

learning of college students. Journal of Vocational Behavior, 37(2), 223-238.

Mulholand, J., \& Wallace, J. (2001). Induction and elementary science teaching: Enhancing self-efficacy. Teaching and Teacher Education, 17(2), 243-261.

Pajares, F. (1994). Inviting self-efficacy: The role of invitations in the development of confidence and competence in writing. Journal of Invitational Theory and Practice, 3(1), 5-11.

Pajares, F., Johnson, M. J., \& Usher, E. L. (2007). Sources of writing self-efficacy beliefs of elementary, middle, and high school students. Research in the Teaching of English, 42(1), 104-120. 
Palmer, D. H. (2006). Sources of self-efficacy in a science methods course for primary teacher education students. Research in Science Education, 36(4), 337-356.

Polou, M. (2007). Personal teaching efficacy and its sources: Student teachers' perceptions. Educational Psychology, 27(2), 191-218.

Polydoro, S., Winterstein, P. J., Azzi, R. G., Carmo, A. P., \& Venditti, R. Jr. (2004). Escala de autoeficácia do professor de Educação Física. In C. Machadon, L. S. Almeida \& M. V. Gonçalves (Org.). Avaliação psicológica: Formas e contextos (pp. 330-337). Braga: Psiquilíbrios.

Prieto, L. N. (2005). Las crencias de autoeficacia docente del profesorado universitário. Tesis doctoral no publicada, Universidad Pontificia Comillas de Madrid. Recuperado em 20 jul. 2010, em http://www. des.emory.edu/mfp/PrietoInstrument.pdf

Stevens, T., Olivárez, A. Jr., \& Hamman, D. (2006). The role of cognition, motivation, and emotion in explaining the mathematics achievement gap between Hispanic and White students. Hispanic Journal of Behavioral Sciences, 28(2), 161-186.

Tschannen-Moran, M., Woolfolk Hoy, A., \& Hoy, W. K. (1998). Teacher efficacy: Its meaning and measure. Review of Educational Research, 62(2), 202-248.

Tschannen-Moran, M., \& Hoy, W. K. (2000). A multidisciplinary analysis of the nature, meaning, and measurement of trust. Review of Educational Research, 70(4), 547-593.
Tschannen-Moran, M., \& Woolfolk Hoy, A. (2001). Teacher efficacy: Capturing an elusive construct. Teaching and Teacher Education, 17, 783-805.

Tschannen-Moran, M., \& Gareis, C. R. (2004). Principals' sense of efficacy: Assessing a promising construct. Journal of Educational Administration, 42(5), 573-585.

Usher, E. L., \& Pajares, F. (2006). Sources of academic and self-regulatory efficacy beliefs of entering middle school students. Contemporary Educational Psychology, 31(2), 125-141.

Woolfolk Hoy, A., \& Burke Spero, R. (2005). Changes in teacher efficacy during the early years of teaching: A comparison of four measures. Teaching and Teacher Education, 21(4), 343-356.

Zimmerman, B. J. (1995). Self-efficacy and educational development. In A. Bandura (Ed.). Self-efficacy in changing societies (pp. 202-231). Cambridge: Cambridge University Press.

Zimmerman, B. J., \& Cleary, T. J. (2006). Adolescents' development of personal agency: The role of self-efficacy beliefs and self-regulatory skill. In F. Pajares \& T. Urdan (Ed.). Self-efficacy beliefs of adolescents (pp. 45-70). Greenwich: Information Age Publishing. 